\title{
Relative Sliding Durability of Two Candidate High Temperature Oxide Fiber Seal Materials
}

Christopher DellaCorte and Bruce M. Steinetz Lewis Research Center Cleveland, Ohio

September 1991

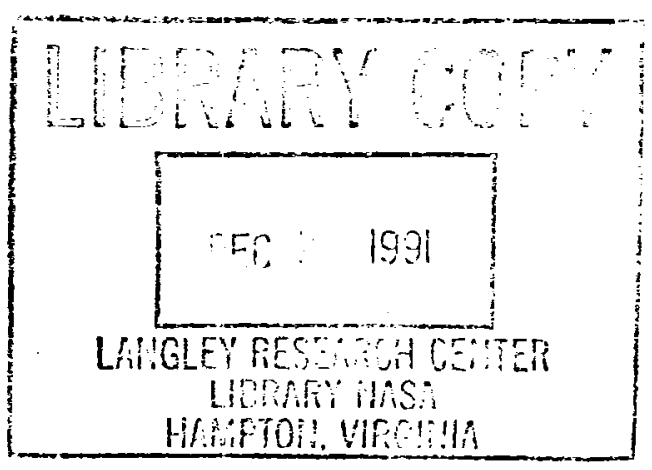

\section{N/Sก}


$j$ 


\title{
RELATIVE SLIDING DURABILITY OF TWO CANDIDATE HIGH TEMPERATURE
}

\section{OXIDE FIBER SEAL MATERIALS}

\author{
Christopher DellaCorte and Bruce M. Steinetz \\ National Aeronautics and Space Administration \\ Lewis Research Center \\ Cleveland, Ohio 44135
}

\section{SUMMARY}

A test program to determine the relative sliding durability of two candidate ceramic fibers for high temperature sliding seal applications is described. Pin on disk tests were used to evaluate potential seal materials. Friction was measured during the tests and fiber wear, indicated by the extent of fibers broken in a test bundle or yarn, was measured at the end of a test.

In general, friction and wear increase with increased test temperature. This may be due to a reduction in fiber strength, a change in the surface chemistry at the fiber/counterface interface due to oxidation and/or adsorption or desorption of surface species and, to a lesser extent, an increase in counterface surface roughness due to oxidation at elevated temperatures. The relative fiber durability correlates with tensile strength indicating that tensile data, which is more readily available than sliding durability data, may be useful in predicting fiber wear behavior under various conditions. A simple model developed using dimensional analysis shows that the fiber durability is related to a dimensionless parameter which represents the ratio of the fiber strength to the fiber stresses imposed by sliding.

\section{INTRODUCTION}

Advanced propulsion systems such as the new generation of launch vehicles and especially hypersonic vehicles such as NASP, illustrated in figure 1, will push engine material and system requirements to higher temperatures (ref. 1). New materials like metal and ceramic matrix composites are currently under development for these applications (ref. 2). In addition, new technologies and approaches for control surface bearings and seals will be needed to meet these future applications.

Several proposed hypersonic vehicles will, for example, require sliding seals to operate in adverse environments encountered in engines and on control surfaces such as flaps and elevons. It has been estimated that linear sliding seals will be needed to seal the airframe structure from the heat of combustion in the engine and the frictional heat of the airstream and may need to operate successfully at temperatures near $1000^{\circ} \mathrm{C}$ (ref. 3). Since no current technology can meet these types of challenges development programs are currently underway at NASA to develop suitable seals.

One current approach to solve some of these advanced sealing problems is to use a braided linear rope seal in sliding contact with a cooled metallic counterface (ref. 4). The rope seal is woven from ceramic fibers and is required to be able to withstand oxidative and reducing environments, which may contain water vapor, at temperatures to about $1000^{\circ} \mathrm{C}$. Figure 2 shows, schematically, one such rope seal design. 
For long seal life and low seal actuation forces, friction and wear of the rope must be minimized. Recent research suggests that, in sliding contacts, unlubricated ceramics exhibit high friction and wear (ref. 5). Therefore, the determination and understanding of high temperature friction and wear properties of candidate seal materials are important issues.

The following paper attempts to address these issues. In this paper, two candidate ceramic fiber materials based on the $\mathrm{Al}_{2} \mathrm{O}_{3}-\mathrm{SiO}_{2}-\mathrm{B}_{2} \mathrm{O}_{3}$ system, Nextel 312 and Nextel 440, are compared by sliding them against Inconel 718 counterface disks at temperatures from 25 to $900{ }^{\circ} \mathrm{C}$ under simulated seal conditions. The goal of the paper is twofold. One goal is to compare the relative durability of these two ceramic candidate materials and assess their potential for seal use. The second goal is to develop a convenient screening technique to evaluate other potential fiber materials.

\section{APPARATUS AND PROCEDURES}

Since many new fibers are available in limited quantities it is advantageous to have a screening technique that requires a minimum of material and minimal specimen preparation yet simulates the anticipated seal application. The pin on disk test satisfies these needs. To conduct a test, a bundle of the fiber material to be tested, which typically contains $\approx 6000$ fibers, $\approx 11 \mu \mathrm{m}$ in diameter, is wrapped over the end a hemispherically tipped pin then loaded against a rotating counterface disk surface. Friction is continuously monitored during the test and fiber wear, which is determined by the number of fibers that break during sliding, is measured after testing.

This testing approach is a variation of the author's work done previously on woven fabric materials (ref. 6). In that work, samples of woven ceramic fabric to be tested were draped over the end of a hemispherically tipped pin and rubbed against metal and ceramic test disks. The approach was successful but required a substantial amount of woven fabric for each sample. Many of the newly emerging ceramic fiber materials are not available in woven form and are only available as simple strands or bundles of fibers and in small quantities. Therefore, it was important to develop a technique to test a bundle of fibers in sliding to assess durability using a minimum amount of material.

To achieve this requirement in this work, a short bundle of fibers is draped over the end of a specially machined Inconel 718 pin and held in place with loops of circumferentially wound stainless steel wire (fig. 3). The pin has grooves machined into the tip and shank to accept the bundle and prevent its slipping off during testing. As in the previous work with the woven fabric (ref. 6), the pin has a small flat spot at its tip, $3.2 \mathrm{~mm}$ in dianieter, to better support the fiber bundle and provide a uniform sliding area. The bundle is given a one half or $180^{\circ}$ twist across the flat contact spot to help contain the bundle in the sliding contact and to orient the fibers at approximately a $45^{\circ}$ angle with the sliding direction to better simulate proposed braided seal configurations (fig. 4).

To test a fiber candidate, a bundle of fibers, usually containing about $6000,11 \mu \mathrm{m}$ diameter fibers, is mounted on the pin specimen. The pin is then slid against a counterface disk in a high temperature pin on disk tribometer. The disk is $63.5 \mathrm{~mm}$ in diameter and $12.7 \mathrm{~mm}$ thick. The pin generates a $51 \mathrm{~mm}$ wear track on the face of the disk. 
Figure 5 shows a schematic of the tribometer used in this work. The tribometer has been described in detail elsewhere (ref. 7) and its main features will only be briefly described here.

The pin on disk tribometer is capable of sliding pin on disk specimens at loads from 0.1 to $100 \mathrm{~kg}$ at sliding speeds from 0.025 to $22 \mathrm{~m} / \mathrm{s}$. The specimens can be heated using a $\mathrm{SiC}$ glowbar furnace to temperatures of $1200^{\circ} \mathrm{C}$. For the tests conducted here, the sliding speed was $0.025 \mathrm{~m} / \mathrm{s}$ and the load was $0.270 \mathrm{~kg}$. The test atmosphere was ambient air with a relative humidity ranging from 50 to 75 percent at $25{ }^{\circ} \mathrm{C}$. Test temperature was 25,500 and $900{ }^{\circ} \mathrm{C}$. The test duration was $120 \mathrm{~min}$. Friction was continuously measured during the tests. Wear was qualitatively monitored during the tests using an LVD'T position sensor on the pin specimen and more exactly quantified after each test. By monitoring pin movement during the test, excessive fiber breakage can be detected and sliding can be suspended prior to the end of the typical two hr test period. Preliminary tests indicated that fiber wear occurs in a fairly uniform manner during the tests. Fiber wear data, within an uncertainty of about 5 percent, was determined using SEM micrographs and from post test visual observations. The results from both of these techniques agree well.

\section{MATERIALS}

The materials tested in this test program consist of two candidate fiber materials with two different thermal treatments and one disk counterface material. The fibers tested were $3 \mathrm{M}$ 's Nextel 312 and Nextel 440. The fiber composition and mechanical properties are given in detail in table I. The fibers are made from alumina, boria and silica. Nextel 312 contains more of the glass former, boria, at $14 \mathrm{wt} \%$, than Nextel 440 which contains only $2 \mathrm{wt} \%$ boria. Nextel 312 , therefore, is more amorphous and glasslike and also has, in general, lower tensile strength than Nextel 440.

The fibers tested, were slightly oval in cross section with diameters of about $11 \mu \mathrm{m}$. All of the samples were heat cleaned at $500{ }^{\circ} \mathrm{C}$, in air for $1 \mathrm{hr}$ to remove an organic sizing cornpound used by the manufacturer during processing (ref. 10). Furthermore, some samples which are designated with an HT suffix, Nextel $440 \mathrm{HT}$ for example, were heat treated in air at $950{ }^{\circ} \mathrm{C}$ for $12 \mathrm{hr}$ to make the fibers more resistant to moisture degradation at temperature. In general, this heat treatment slightly lowers the tensile strength of the fibers (ref. 8).

The test disks were made of Inconel 718, a precipitation hardened nickel-chromium alloy. Table II gives the composition and hardness of the disk material. This material is being considered as a possible candidate for seal applications because of its high temperature strength and oxidation resistance. Prior to testing, the disk surface is lapped with alumina abrasive to a surface finish of about $0.1 \mu \mathrm{m}$ rms. After lapping, the specimens are cleaned with freon, ethyl alcohol, scrubbed with a paste of levigated alumina and deionized water, rinsed with deionized water and air dried.

\section{RESULTS}

The friction and wear results for the tests conducted are given in table III. Wear is given by cycles to failure, CTF which is a common wear parameter for fiber materials (ref. 9). For these tests, the CTF is determined by first dividing the number of cycles tested by the number of fibers broken during the test and then multiplying by the total number of fibers in the bundle 
tested (in our case there are 6000 fibers). For example, if 50 percent of the fibers in a bundle (3000 fibers) break after a two hr test (1200 revolutions or cycles) the CTF is (1200). $(6000 / 3000)=2400$. That is to say it would take 2400 disk revolutions or cycles to break through the entire 6000 fiber bundle.

This measurement assumes that the fiber breakage rate is linear with time and is therefore, simplistic. However, CTF is a standard comparative measure for fiber durability in the textile industry and proves to be a useful measurement for these tests.

The friction data for the four test specimen combinations evaluated are given in table III and a typical friction plot is given in figure 6. Each data curves in this plot represents the average of at least three experiments. The data scatter values are shown in table III. From the data it can be seen that the friction coefficients at 500 and $900{ }^{\circ} \mathrm{C}$ are higher than at room temperature. This may be due to oxidation of the disk surface or the desorption of surface species on the specimens such as water vapor. Although there is a slight decrease in friction from 500 to $900{ }^{\circ} \mathrm{C}$ this variation is well within data scatter.

\section{DISCUSSION}

Considering the CTF data, a ranking of the durability of the fibers can clearly be seen. The most durable fiber is the Nextel 440 followed by the heat treated 440 , Nextel 312 and finally Nextel 312 in the heat treated condition. This ranking holds true for all of the temperatures tested. To better understand the reason for this ranking it is instructive to first examine the surface features of the worn fiber specimens and then combine those observations with the fibers' mechanical and physical properties.

\section{MORPHOLOGICAL ASPECTS}

Much can be learned about tribological tests by examining the wear surfaces as well as the numerical data values. Figures 7 to 9 show SEM photomicrographs of fiber bundles after sliding against the counterface disk. One apparent aspect is that the fiber bundles are wearing by brittle fracture and not be gentle abrasion. This finding is consistent with work done previously (ref. 6). Also noted is that little debris, transferred disk material or reaction products seem to be present. This is coincident with the fact that the Nextel 312 and 440 fibers tested are oxide ceramics which would not normally react in an air environment at these modest test temperatures.

Surface profilometry of the disk surfaces before and after testing indicate that, due to surface oxidation, the disk surface is rougher after elevated temperature runs than after room temperature runs. Although the arithmetic roughness parameter, $R_{a}$, increases three fold (table IV), the surfaces are still fairly smooth and don't seem to have an effect on the fiber durability. Further tests are required to determined the level of roughness which will cause an increase in fiber breakage. The major observation of the wear surfaces are that the fibers are failing in a brittle fracture mode and that the disk surface is, due to the growth of an oxide layer, somewhat roughened.

Table $\mathrm{V}$ shows the tensile strength as a function of temperature for the four fiber conditions tested. From the data in the tables III and V, it can be seen that the ranking of the fibers in 
terms of tensile strength is the same as the ranking of the fibers in terms of CTF or durability. Although the correlation of the rankings of the fiber durability and tensile strength is good, a mathematical or functional relationship between CTF and tensile strength is not immediately apparent. To better understand the factors affecting the fiber durability a dimensional analysis of the fiber durability and the factors affecting the CTF was conducted.

\section{DIMENSIONAL ANALYSIS}

A power product method of dimensional analysis was utilized to determine potentially meaningful dimensionless parameters and a possible relationship between fiber durability and tensile strength. This technique consists of setting an arbitrary relationship between the desired measurand, the CTF, and the probable factors affecting it. In our case the C'TF is likely to be affected by fiber tensile strength(TS), fiber cross section area(A), friction coefficient $(\mu)$ and $\operatorname{load}\left(F_{n}\right)$, temperature $(t)$ and counterface surface roughness $\left(R_{a}\right)$. Mathematically:

$$
\mathrm{CTF}=f\left(\mathrm{TS}, \mathrm{A}, \mu \cdot \mathrm{F}_{\mathrm{n}}, \mathrm{t}, \mathrm{R}_{\mathrm{a}}\right)
$$

Since temperature directly affects the fiber tensile strength and the load is constant, we can eliminate temperature and combine the friction coefficient and the load force into one variable, the friction force, $\mathrm{F}_{\mathrm{f}}$.

Written as a power product the relation is as follows:

$$
\mathrm{CTF}=\mathrm{K} \cdot(\mathrm{TS})^{\mathrm{a}} \cdot(\mathrm{A})^{\mathrm{b}} \cdot\left(\mathrm{F}_{\mathrm{f}}\right)^{\mathrm{c}} \cdot\left(\mathrm{R}_{\mathrm{a}}\right)^{\mathrm{d}}
$$

where $\mathrm{K}$ is an arbitrary constant or a function of other variables held constant in these tests (e.g., total numbers of fibers).

To determine the values of the powers a-d, a dimensional analysis is used, equating the units in each parameter to match the nondimensional nature of the CTF. Substituting for the units contained in each parameter and separating for each unit gives:

$$
\{0\}=1 \cdot\left\{\mathrm{Fm}^{-2}\right\}^{\mathrm{a}} \cdot\left\{\mathrm{m}^{2}\right\}^{\mathrm{b}} \cdot\{\mathrm{F}\}^{\mathrm{c}} \cdot\{\mathrm{m}\}^{\mathrm{d}}
$$

for force, $\mathrm{F}: \quad 0=\mathrm{a}+\mathrm{c}$

for length, $m: 0=-2 a+2 b+d$

Since there are two equations and four unknowns the results will be somewhat arbitrary but the assumptions made can be verified by the data and may prove to be useful.

If we let: $a=1$ then $c=-1$.

Then using the equation for length:

$\mathrm{m}: 2=2 \mathrm{~b}+\mathrm{d}$ 
If it is assumed that the surface roughness effect is small for these tests, i.e., $d \approx 0$, then: $b=1$ and the following relation is found:

$$
\mathrm{CTF}=\mathrm{K} \cdot(\mathrm{TS} \cdot \mathrm{A}) /\left(\mathrm{F}_{\mathrm{f}}\right)
$$

If we then substitute the fiber diameter squared, $D^{2}$, for the area, incorporating the $\pi / 4$ term in the constant and expand the friction force back to the product of the friction coefficient and the load, the relation is as follows:

$$
\mathrm{CTF}=\mathrm{K} \cdot\left(\mathrm{TS} \cdot \mathrm{D}^{2}\right) /\left(\mu \cdot \mathrm{F}_{\mathrm{n}}\right)
$$

This relationship gives the fiber durability in terms of a durability ratio which incorporates fiber and test condition parameters. The numerator is essentially a measure of the fiber breakage strength and the denominator is a measure of the applied friction force which acts to break the fibers.

To assure the validity of the assumption to neglect the surface roughness, fiber durability tests were conducted at various roughnesses where all other parameters are held constant. Results from these tests are shown in table VI. Clearly, over the range of surface roughnesses tested the fiber durability is not greatly affected. This may not be the case for different fibers or slightly more roughened surfaces. More research is underway to determine the limits of the assumption to neglect surface roughness. For the tests discussed here, the assumption to neglect roughness in the $\mathrm{CTF}$ relation is justified.

The relationship established by the dimensional analysis and the identification of an important dimensionless parameter helps to explain and understand the data. The usefulness of the analysis and the dimensionless durability ratio or parameter can be seen by examining a plot of fiber durability (CTF) versus the durability ratio (TS $\cdot \mathrm{D}^{2} / \mu \mathrm{F}_{\mathrm{n}}$ ) as shown in figure 10 . Though the data is not comprehensive, a trend is apparent. That is that, rather than a simple linear function, the CTF seems to be a step function of fiber strength to fiber breakage forces. Others have found similar connections between ceramic wear and fracture behavior (ref. 11).

The CTF is low for (TS $\cdot \mathrm{D}^{2} / \mu \mathrm{F}_{n}$ ) ratios lower than about 0.12. Above this point the CTF rises dramatically. This implies that a threshold exists around a ratio of 0.12 below which poor fiber durability is exhibited and above which good fiber durability is observed.

Much of the data scatter in figure $\mathbf{1 0}$ may be the result of uncertainties in the tensile strength data which in some cases was extrapolated from data at other temperatures and also friction data scatter. Nonetheless the dimensional analysis model helps to delineate the important variables and helps to explain the data we measure.

For example, the model clearly explains why the fibers with higher tensile strength exhibit more durability. Also, the gain in strength must be tempered by a possible increase in friction or load which cause the frictional stresses on the fibers to increase. This indicates that durability can be enhanced by reducing the loads or by lubricating the fibers. Both of the options are available to seal designers and have been shown to be effective in previous research with these materials in woven fabric form (refs. 6 and 8).

Although the data scatter is large, figure $\mathbf{1 0}$ can be used to determine the approximate value of the threshold separating durability behavior for this materials system. It must be 
pointed out, however, that this value is only crudely approximate. More data on other fiber materials needs to be acquired to ensure better accuracy. Also, this analysis is based upon mechanics and data taken where physical properties seem to dominate chemical ones. For other materials systems, chemical reactivity with the environment and other materials in the environment may have a significant impact on durability.

\section{CONCLUSIONS}

The relative durability of two fiber materials in two conditions were evaluated using a pinon-disk tribometer. The test technique developed provided repeatable data in a convenient manner using a minimal amount of test material. The test results and observations were consistent with the brittle behavior of ceramic materials in sliding contact and corroborated research done previously with these ceramic fiber materials in woven fabric form. Based upon these tests the following specific conclusions can be drawn:

1. In terms fiber durability, Nextel 440 without the heat treatment is the most durable fiber material.

2. In these tests where the friction coefficients were comparable, the fiber durability ranking correlates well with the tensile strength ranking indicating that tensile data may provide insight for seal material selection and screening.

3. Over the limited roughness range studied here, surface roughness had no measurable effect on fiber durability.

4. Fiber durability decreased and friction increased with temperature. This may be due to a variety of factors including lower fiber strength and possible changes in the chemistry of the fiber/counterface sliding contact.

5. A simple model developed from a dimensional analysis indicates that fiber durability is related to a durability ratio of the fiber strength to the frictional stresses imposed on the fibers due to sliding.

\section{ACKNOWLEDGMENTS}

The author would like to thank Mr. V. Lukaszewicz for preparing the fiber specimens and for conducting the fiber durability tests. Also, the SEM analyses by Mr. A. Korenyi - Both are appreciated.

\section{REFERENCES}

1. Jaffe, R.I.; Perkins, R.A.; and Pound, G.M., eds.: Hypersonic Vehicles-Performance. HighTemperature Oxidation-Resistant Coatings, National Academy of Sciences, Washington, D.C., 1970, pp. 141-158.

2. Stephens, J.R.: HITEMP Program Overview. HITEMP Review 1990: Advanced High Temperature Engine Materials Technology Program, NASA CP-10051, 1990, pp. 1-23. 
3. Steinetz, B.M.; DellaCorte C.; and Sirocky, P.: On the Development of Hypersonic Engine Seals. NASA TP-2854, 1988.

4. Steinetz, B.M.; DellaCorte, C.; and Tong, M.: Seal Concept and Material Performance Evaluation For the NASP Engine. Proceedings of the Seventh NASP Technology Symposium, Cleveland, OH, Oct. 1989, Paper No. 60.

5. Yust, C.S.; and Allard, L.F.: Wear Characteristics of an Alumina Silicon Carbide Whisker Composite at Temperatures to $800^{\circ} \mathrm{C}$ in Air. Tribology Trans., vol. 32, July 1989, pp. 331-338.

6. DellaCorte, C.: Tribological Properties of Alumina-boria-silicate Fabric From $25{ }^{\circ} \mathrm{C}$ to $850^{\circ} \mathrm{C}$. Tribology Trans., vol. 32, July 1989, pp. 325-330.

7. Sliney, H.E.; and DellaCorte, C.: A New Test Machine for Measuring Friction and Wear in Controlled Atmospheres to $1200^{\circ} \mathrm{C}$. Lubr. Eng., vol. 47, no. 4, Apr. 1991, pp. 314-319.

8. DellaCorte, C; Steinetz, B.M.; and Brindley, P.K.: Tribological Properties of Ceramic/ $\mathrm{Ti}_{3} \mathrm{Al}-\mathrm{Nb}$ Sliding Couples for Use as Candidate Seal Materials to $700{ }^{\circ} \mathrm{C}$. NASA TM-102401, 1990.

9. Miller, B.; Friedman, H.L.; and Turner, R.: Design and Use of a Cyclic Tensile Abrader for Filaments and Yarns - A Study of Polyester Monofilament Wear. Textile Res., vol. 53, no. 12, Dec. 1983, pp. 733-740.

10. Holtz, A.R.; and Grether, M.F.: High Temperature Properties of Three Nextel Ceramic Fibers. Advanced Materials Technology 87 Proceedings of the 32nd International Sampe Symposium, R. Carson, et al., eds., 1987, pp. 245-256.

11. Sliney, H.E.; and Deadmore, D.L.: Friction and Wear of Oxide-Ceramic Sliding Against IN-718 Nickel Base Alloy at 25 to $800^{\circ} \mathrm{C}$ in Atmospheric Air. NASA TM-102291, 1989. 
TABLE I. - COMPOSITION AND PHYSICAL

PROPERTIES OF CANDIDATE CERAMIC

SEAL FIBER MATERIALS ${ }^{a}$

\begin{tabular}{|l|c|c|}
\hline \multicolumn{1}{|c|}{ Property } & Nextel 312 & Nextel 440 \\
\hline Fiber composition, wt \% & $\begin{array}{c}62 \mathrm{Al}_{2} \mathrm{O}_{3} \\
24 \mathrm{SiO}_{2} \\
14 \mathrm{~B}_{2} 0_{3}\end{array}$ & $\begin{array}{c}70 \mathrm{Al}_{2} \mathrm{O}_{3} \\
28 \mathrm{Si}_{2} \\
2 \mathrm{~B}_{2} 0_{3}\end{array}$ \\
\hline Fiber diameter, $\mu \mathrm{m}$ & 10 to 12 & 10 to 12 \\
\hline Density, g/cc & 2.7 to 2.9 & 3.0 \\
\hline $\begin{array}{l}\text { Filament tensile } \\
\text { strength }(5 \mathrm{~mm} \text { gage), MPa }\end{array}$ & 1700 & 2000 \\
\hline Filament tensile modulus, GPa & 150 & 190 \\
\hline Surface area, $\mathrm{m}^{2} / \mathrm{g}$ & $<0.2$ & $<0.2$ \\
\hline
\end{tabular}

${ }^{\mathrm{a}}$ Taken from reference 10.

TABLE II. - COMPOSITJON AND HARDNESS OF INCONEL TEST DISK SPECIMENS

\begin{tabular}{|c|c|}
\hline Property & Valve \\
\hline Composition, wt $\%$ & $\begin{array}{l}70 \mathrm{Ni}, 16 \mathrm{Cr}, 7.5 \mathrm{Fe}, 2.5 \mathrm{Ti}, 1 \mathrm{Al} \\
1, \mathrm{Co}, 1, \mathrm{Mn}, 0.1 \mathrm{C} \text { and } 0.9 \text { other }\end{array}$ \\
\hline Hardness, Rockwell C & RC34 \\
\hline
\end{tabular}


TABLE III. - FRICTION AND WEAR

(CYCLES TO FAILURE, CTF) DATA SUMMARY

\begin{tabular}{|l|l|c|c|}
\hline Test temperature & \multicolumn{1}{|c|}{ Material } & $\mu$ & CTF, cycles \\
\hline $25{ }^{\circ} \mathrm{C}$ & Nextel 440 & $0.49 \pm 0.09$ & $7366 \pm 2950$ \\
& Nextel 440 HT & $0.54 \pm 0.07$ & $6205 \pm 1550$ \\
& Nextel 312 & $0.59 \pm 0.10$ & $4000 \pm 1455$ \\
& Nextel 312 HT & $0.53 \pm 0.05$ & $3400 \pm 750$ \\
\hline $500{ }^{\circ} \mathrm{C}$ & Nextel 440 & $0.65 \pm 0.13$ & $8677 \pm 3250$ \\
& Nextel 440 HT & $0.80 \pm 0.08$ & $6510 \pm 1028$ \\
& Nextel 312 & $0.68 \pm 0.09$ & $223 \pm 80$ \\
& Nextel 312 HT & $0.66 \pm 0.12$ & $118 \pm 60$ \\
\hline $900^{\circ} \mathrm{C}$ & Nextel 440 & $0.66 \pm 0.11$ & $3181 \pm 800$ \\
& Nextel 440 HT & $0.64 \pm 0.10$ & $281 \pm 60$ \\
& Nextel 312 & $0.74 \pm 0.13$ & $162 \pm 50$ \\
& Nextel 312 HT & $0.76 \pm 0.13$ & $100 \pm 10$ \\
\hline
\end{tabular}

Note: Test atmosphere, air, R.H. 50 to 75 percent; counterface: Inconel 718; Test velocity, $0.025 \mathrm{~m} / \mathrm{s}$; Test load, $0.27 \mathrm{~kg}$. HT designates thermal treatment at $950^{\circ} \mathrm{C}$ for $12 \mathrm{hr}$ to improve humidity resistance at high temperatures.

TABLE IV. - DISK SURFACE ROUGHNESS AFTER OXIDATION/TESTING AT ELEVATED TEMPERATURES

\begin{tabular}{|c|c|}
\hline Test temperature & Roughness $\mathrm{R}_{\mathrm{A}, \mu \mathrm{m}}$ \\
\hline $25^{\circ} \mathrm{C}$ & $0.036 \pm 0.003$ \\
$500^{\circ} \mathrm{C}$ & $0.047 \pm 0.04$ \\
$900^{\circ} \mathrm{C}$ & $0.120 \pm 0.02$ \\
\hline
\end{tabular}


TABLE V. - FILAMENT TENSILE STRENGTH

\begin{tabular}{|l|l|l|l|}
\hline \multirow{2}{*}{$\begin{array}{c}\text { Fiber } \\
\text { material }\end{array}$} & \multicolumn{3}{|c|}{ Tensile strength, MPa } \\
\cline { 2 - 4 } & $25^{\circ} \mathrm{C}$ & $500^{\circ} \mathrm{C}$ & $900^{\circ} \mathrm{C}$ \\
\hline Nextel $440^{\mathrm{a}}$ & $2000^{\mathrm{a}}$ & $1750^{\mathrm{a}}$ & $1500^{\mathrm{a}}$ \\
\hline Nextel 440HT & $1500^{\mathrm{a}}$ & $1300^{\mathrm{b}}$ & $1125^{\mathrm{b}}$ \\
\hline Nextel $312^{\mathrm{a}}$ & $1700^{\mathrm{a}}$ & $1400^{\mathrm{a}}$ & $750^{\mathrm{a}}$ \\
\hline Nextel 312HT & $1250^{\mathrm{a}}$ & $1029^{\mathrm{b}}$ & $551^{\mathrm{b}}$ \\
\hline
\end{tabular}

${ }^{a}$ Data from reference 10 .

${ }^{\mathbf{b}}$ Strength reduction at elevated temperatures estimated from strength reduction of nonheat treated fibers as recommended by fiber manufacturer.

TABLE VI. - FIBER DURABILITY

OF NEXTEL 440HT AS A

FUNCTION OF DISK SURFACE

ROUGHNESS $\Lambda$ T CONSTANT

TEMPERATURE, $25^{\circ} \mathrm{C}$

\begin{tabular}{|c|c|}
\hline Roughness, $\mathrm{R}_{\mathrm{A}}$ in $\mu \mathrm{m}$ & $\mathrm{CTF}$ \\
\hline $0.036 \pm 0.003^{\mathrm{a}}$ & $6205 \pm 1550$ \\
$0.120 \pm 0.020^{\mathrm{b}}$ & $7000 \pm 1550$ \\
$0.680 \pm 0.020^{\mathrm{c}}$ & $6000 \pm 1200$ \\
\hline
\end{tabular}

${ }^{\mathrm{a}}$ Lapped surface.

${ }^{\mathrm{b}}$ Oxidized in air at $900{ }^{\circ} \mathrm{C}$ for $6 \mathrm{hr}$.

${ }^{\mathrm{c}}$ Diamond ground with 150 grit wheel.

Data are averaged values from at least 3 tests. Uncertainties represent data scatter. 


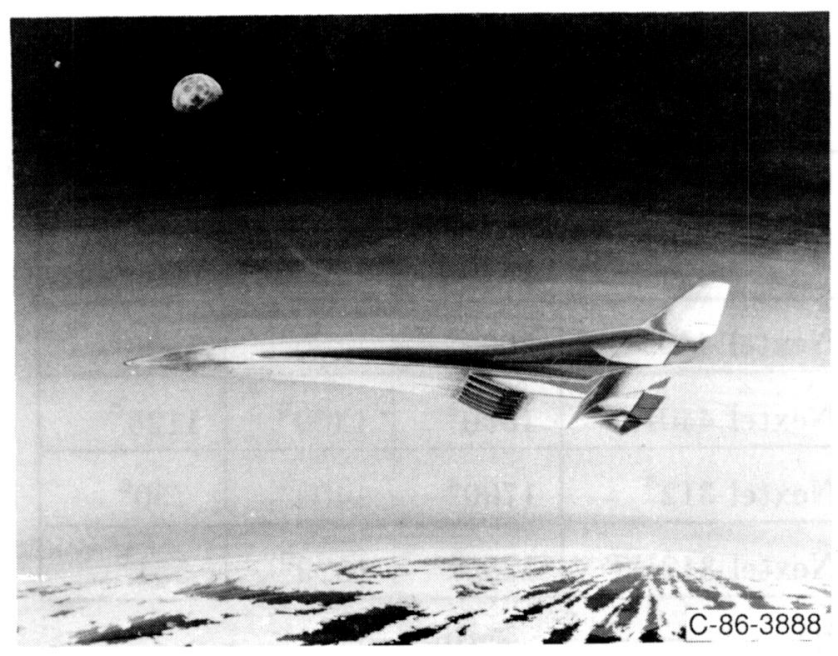

Figure 1.-Artist's conception of hypersonic flight vehicle (NASP).

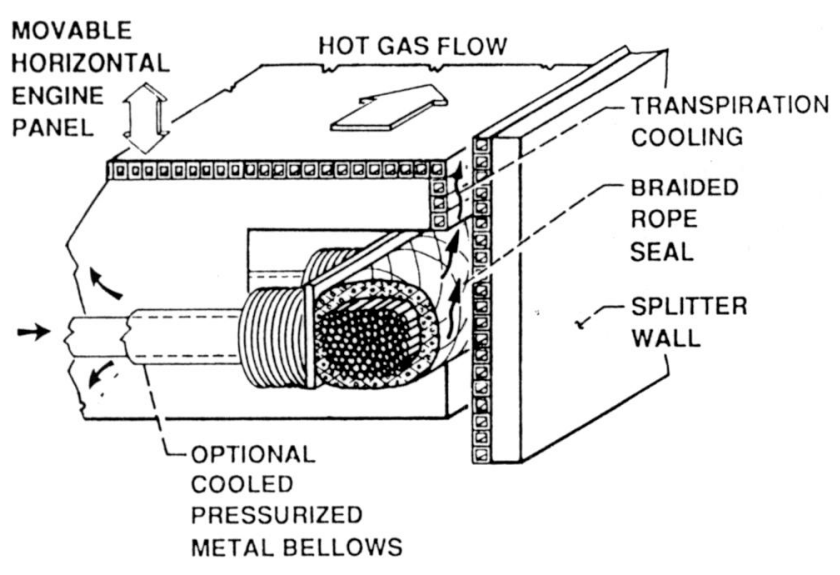

Figure 2.-Cross section of proposed engine seal

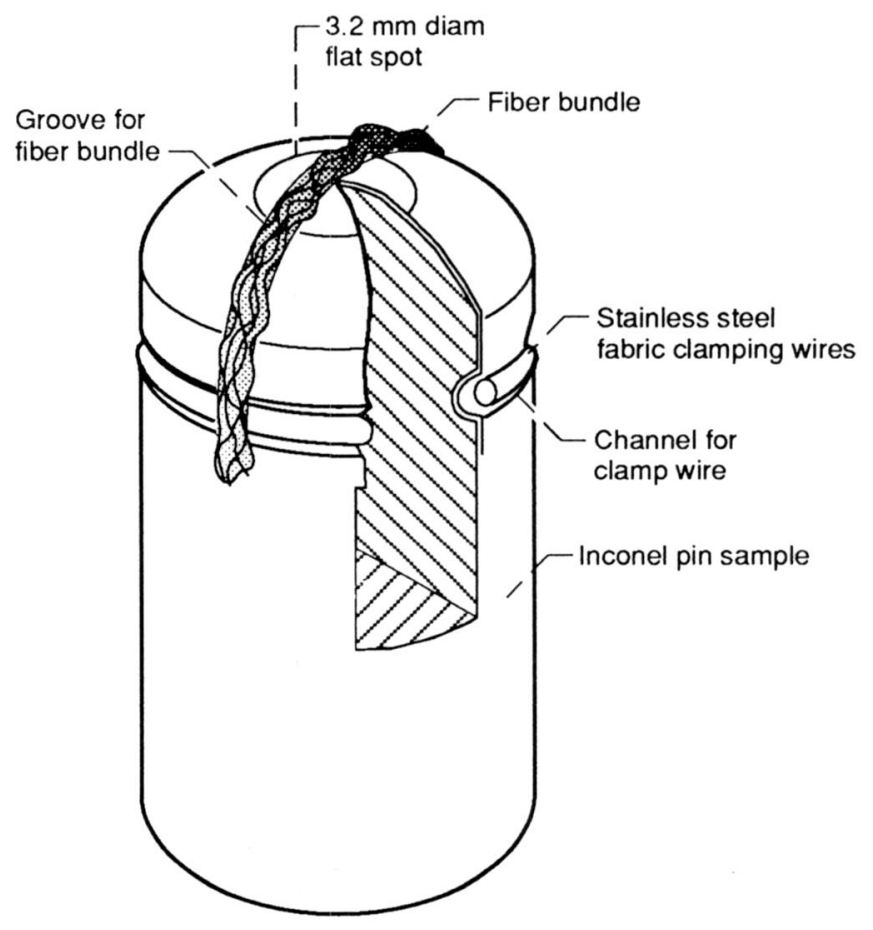

Figure 3.-Pin test specimen 


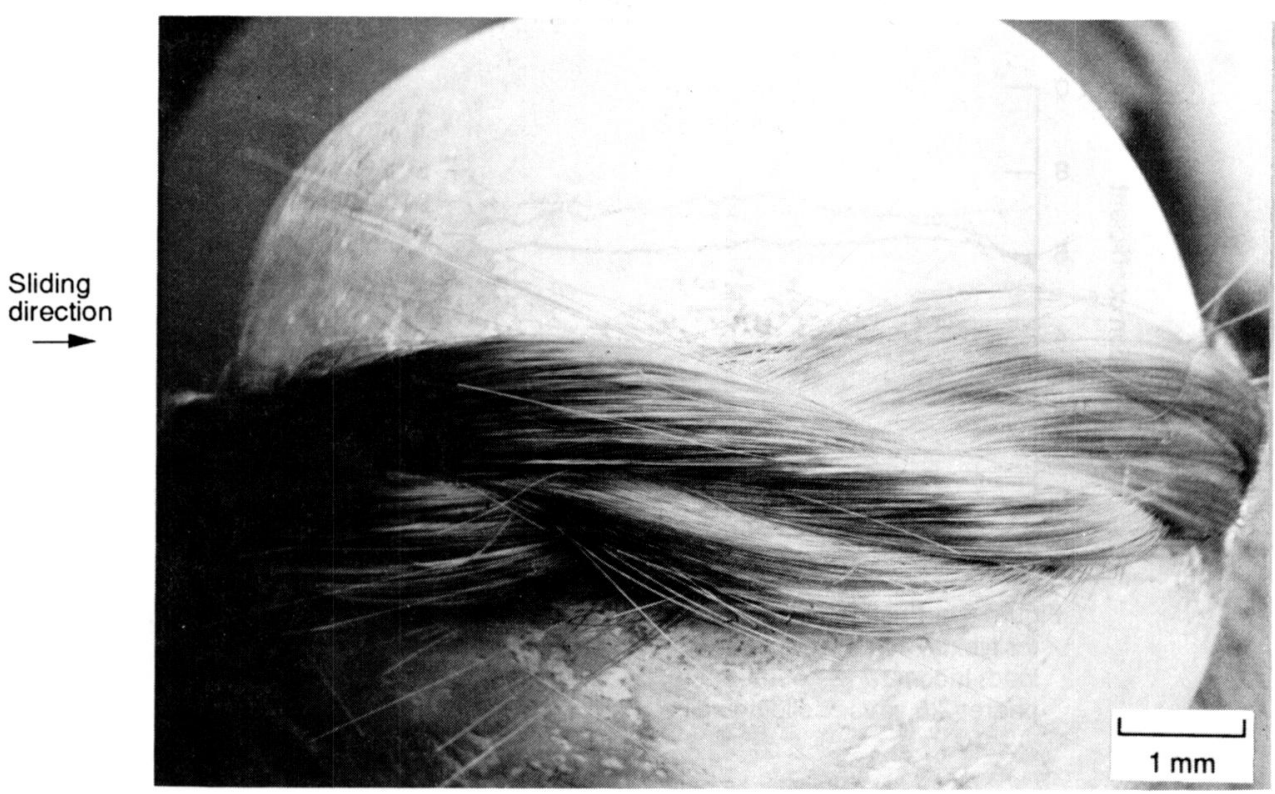

Figure 4.-SEM photomicrograph of fiber-pin specimen prior to testing. Sliding direction is from left to right.

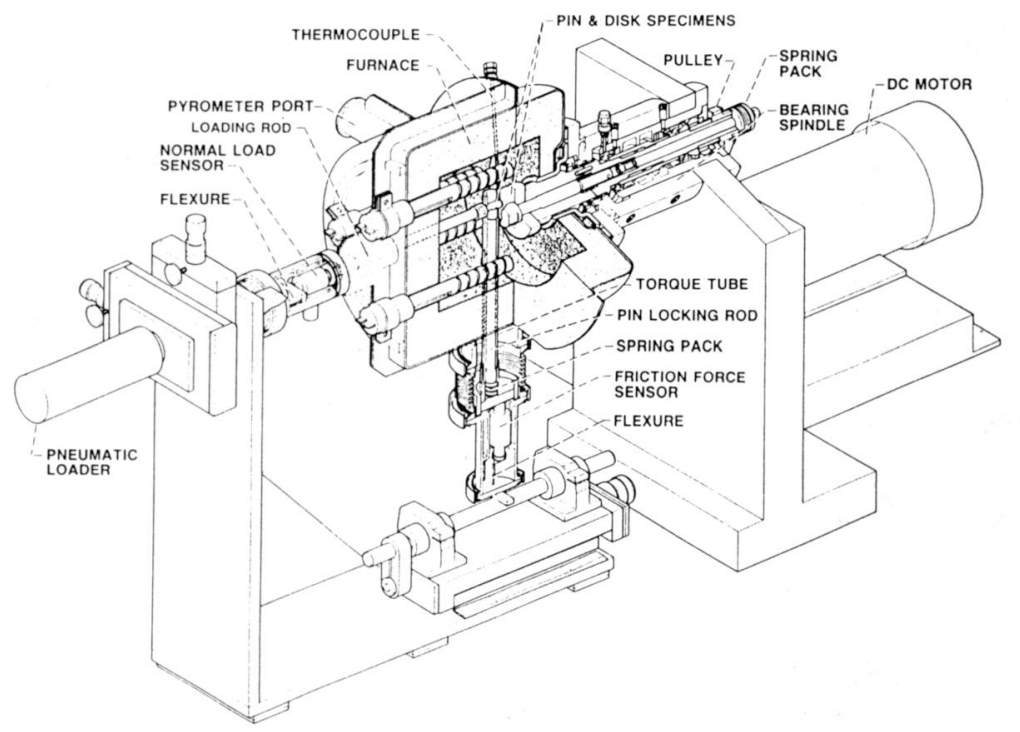

Figure 5.-High-temperature pin on disk tribometer. 


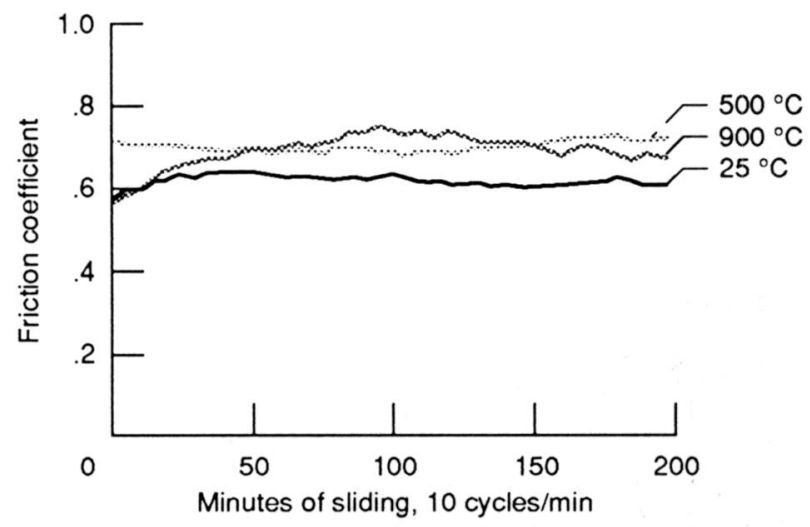

Figure 6.-Friction coefficient versus sliding time for Nextel 440. Test conditions: $0.27 \mathrm{~kg}(2.65 \mathrm{~N})$ load, Inconel 718 counterface disk, air atmosphere, $2.5 \mathrm{~cm} / \mathrm{sec}$ sliding velocity.

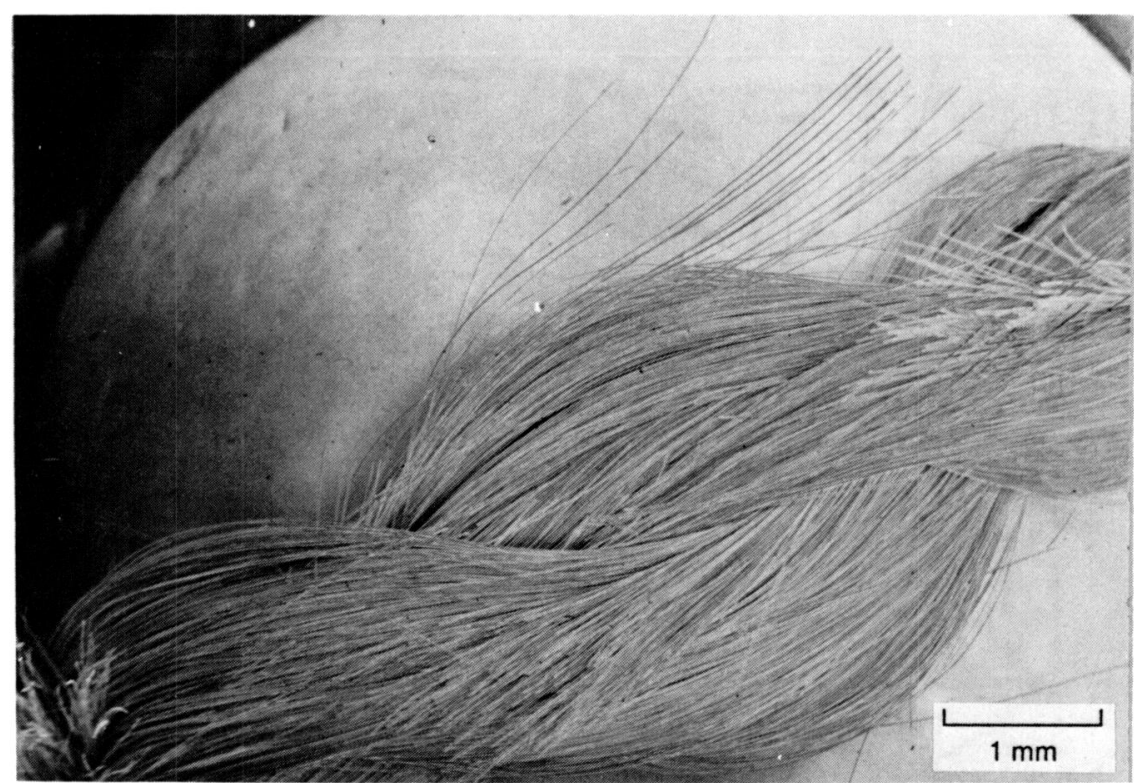

Figure 7.-Nextel 440 fiber-pin specimen after sliding for $24 \mathrm{hr}$ at $25^{\circ} \mathrm{C}$. Very few fibers are broken indicating good durability. 


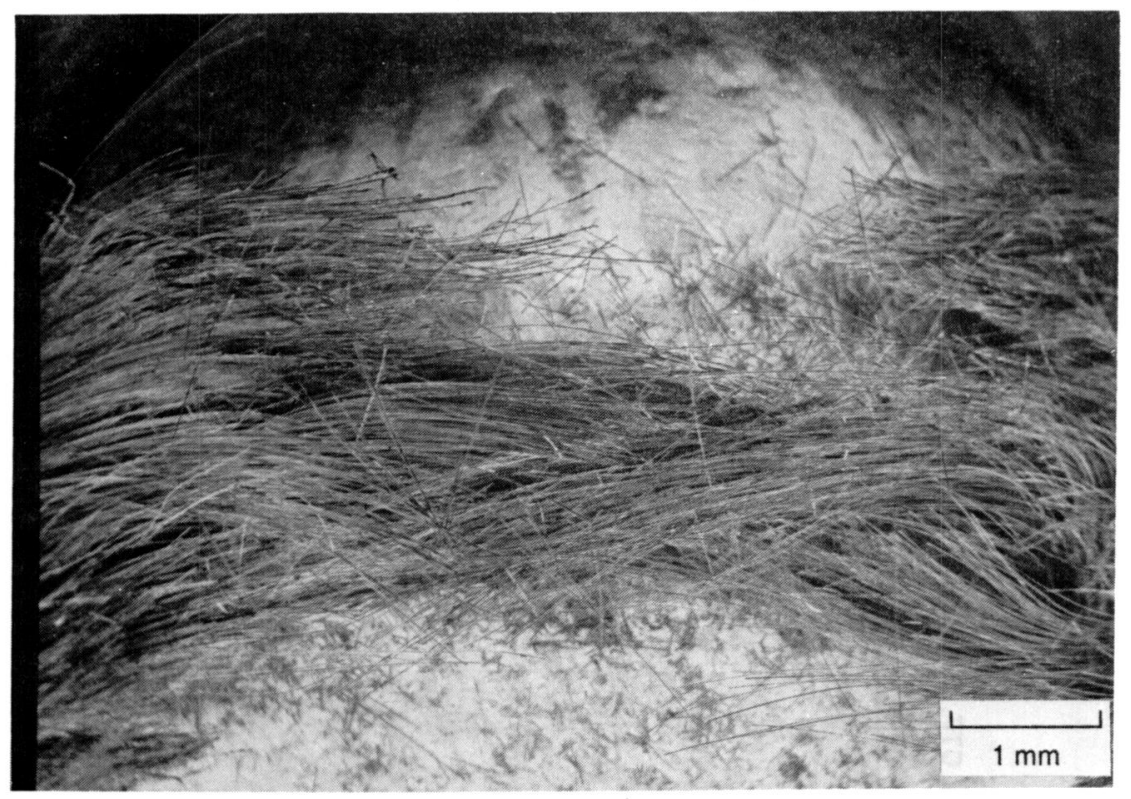

Figure 8.-Nextel $440 \mathrm{Hf}$ fiber-pin specimens after testing at $900^{\circ} \mathrm{C}$. Virtually all of the fibers were broken during the test indicating low durability.

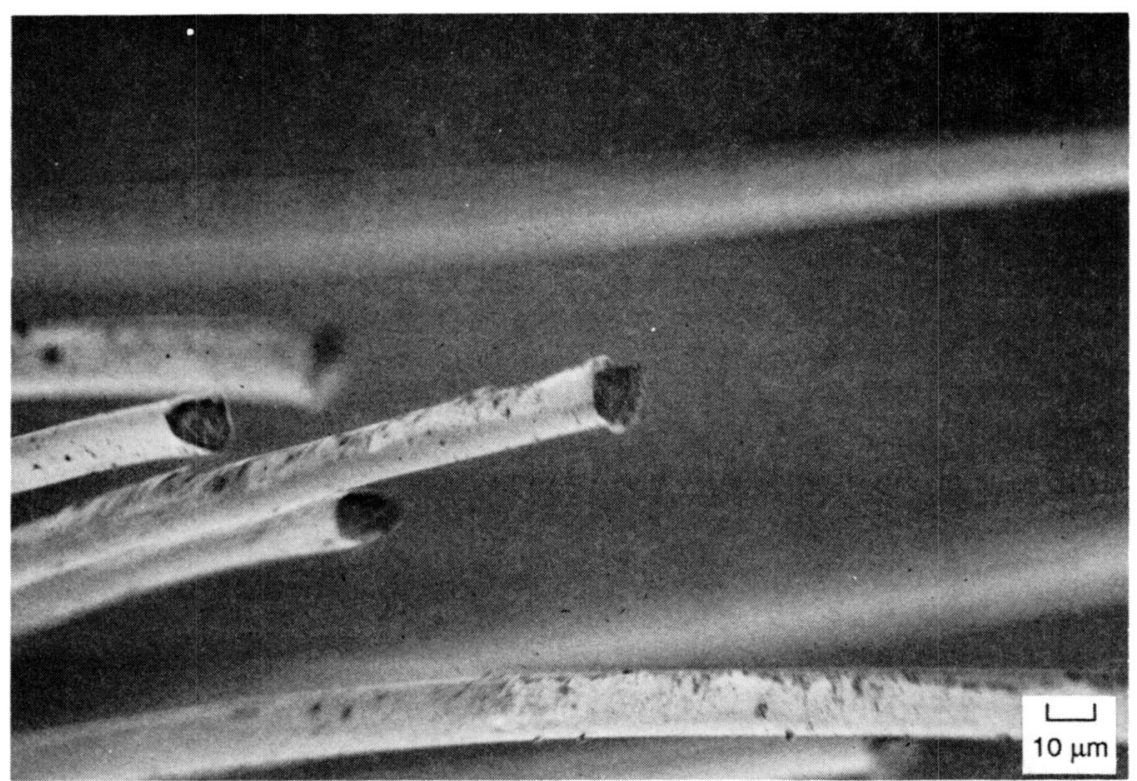

Figure 9.-SEM photomicrograph: Fractured fiber surfaces after sliding at $900^{\circ} \mathrm{C}$. 


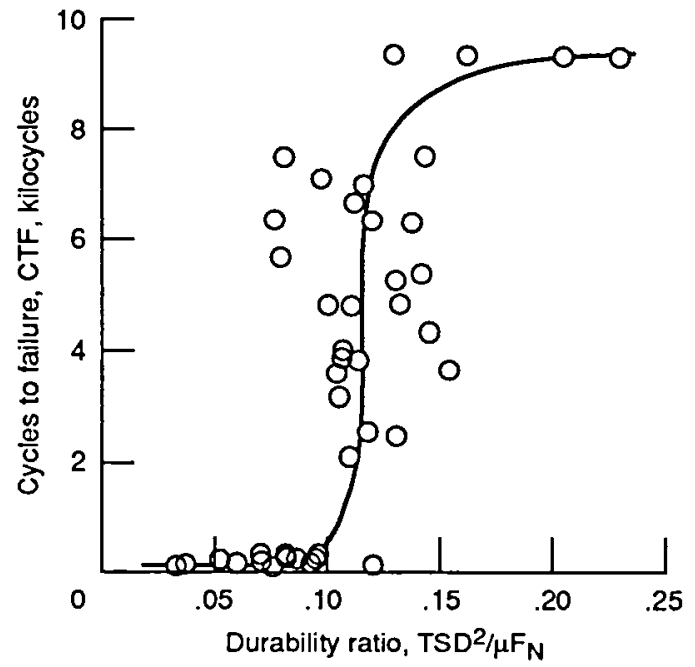

Figure 10.-CTF, cycles to failure, versus durability ratio, $\mathrm{TSD}^{2} / \mu \mathrm{F}_{\mathrm{N}}$, resembles step function with discontinuity or transition occurring between 0.075 and 0.15 . 

Public reporting burden for this collection of information is estimated to average 1 hour per response, including the time for reviewing instructions, searching existing data sources, gathering and maintaining the data needed, and completing and reviewing the collection of information. Send comments regarding this burden estimate or any other aspect of this collection of information, including suggestions for reducing this burden, to Washington Headquarters Services, Directorate for information Operations and Reports, 1215 Jefterson Davis Highway, Suite 1204, Arlington, VA 22202-4302, and to the Office of Management and Budget, Papenwork Reduction Project (0704-0188), Washington, DC 20503.

\begin{tabular}{|l|l|l}
\hline 1. AGENCY USE ONLY (Leave blank) & $\begin{array}{c}\text { 2. REPORT DATE } \\
\text { September } 1991\end{array}$ & $\begin{array}{r}\text { 3. REPORT TYPE AND DATES COVERED } \\
\text { Technical Memorandum }\end{array}$ \\
\hline
\end{tabular}

\section{TITLE AND SUBTITLE}

5. FUNDING NUMBERS

Relative Sliding Durability of Two Candidate High Temperature

Oxide Fiber Seal Materials

6. AUTHOR(S)

Christopher DellaCorte and Bruce M.Steinetz

WU $-505-63-1 A$

\section{PERFORMING ORGANIZATION NAME(S) AND ADDRESS(ES)}

National Aeronautics and Space Administration

Lewis Research Center

Cleveland, Ohio 44135-3191

8. PERFORMING ORGANIZATION REPORT NUMBER

E- 6502

\section{SPONSORING/MONITORING AGENCY NAMES(S) AND ADDRESS(ES)}

10. SPONSORING/MONITORING

National Aeronautics and Space Administration

Washington, D.C. 20546-0001

NASA TM -105199

11. SUPPLEMENTARY NOTES

Responsible person, Christopher DellaCorte, (216) 433-6056.

12a. DISTRIBUTION/AVAILABILITY STATEMENT

12b. DISTRIBUTION CODE

Unclassified - Unlimited

Subject Category 23

13. ABSTRACT (Maximum 200 words)

A test program to determine the relative sliding durability of two candidate ceramic fibers for high temperature sliding seal applications is described. Pin on disk tests were used to evaluate potential seal materials. Friction was measured during the tests and fiber wear, indicated by the extent of fibers broken in a test bundle or yarn, was measured at the end of a test. In general, friction and wear increase with test temperature. This may be due to a reduction in fiber strength, a change in the surface chemistry at the fiber/counterface interface due to oxidation, adsorption and/or desorption of surface species and, to a lesser extent, an increase in counterface surface roughness due to oxidation at elevated temperatures. The relative fiber durability correlates with tensile strength indicating that tensile data, which is more readily available than sliding durability data, may be useful in predicting fiber wear behavior under various conditions. A simple model developed using dimensional analysis shows that the fiber durability is related to a dimensionless parameter which represents the ratio of the fiber strength to the fiber stresses imposed by sliding.

14. SUBJECT TERMS

Seals; Friction; Wear; Fibers; High temperatures

17. SECURITY CLASSIFICATION OF REPORT Unclassified
18. SECURITY CLASSIFICATION OF THIS PAGE Unclassified

\begin{tabular}{|c|c|}
\hline & $\begin{array}{c}\text { 15. NUMBER OF PAGES } \\
18\end{array}$ \\
\cline { 2 - 2 } & $\begin{array}{c}\text { 16. PRICE CODE } \\
\text { A03 }\end{array}$ \\
\hline $\begin{array}{c}\text { 19. SECURITY CLASSIFICATION } \\
\text { OF ABSTRACT } \\
\text { Unclassified }\end{array}$ & 20. LIMITATION OF ABSTRACT \\
\hline
\end{tabular}


National Aeronautics and Space Administration

Lewis Research Center

Cleveland, Ohio 44135

Orficial Business

Penalty for Private Uee $\$ 300$
FOURTH CLASS MAIL

ADDRESS CORRECTION REQUESTED

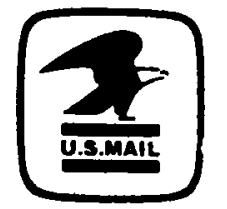

Postage and Fees Paid National Aeronaulics and Space Administration

NASA 451 